\title{
Small numbers of Chlamydia trachomatis elementary bodies on slides detected by the polymerase chain reaction
}

\author{
C B Gilroy, B J Thomas, D Taylor-Robinson
}

\begin{abstract}
A method is described in which smears on slides, which had been examined previously in a direct fluorescence antibody (DFA) test for Chlamydia trachomatis, were tested by the polymerase chain reaction (PCR). Twenty four (73\%) of 33 smears which contained fewer than 10 elementary bodies when examined by the DFA test were positive by the PCR. Of the nine negative smears, seven contained only one or two elementary bodies. However, single elementary bodies were detected by the PCR in seven of the 24 positive samples. Fifteen smears were negative by both methods.

The ability to detect small numbers of elementary bodies by the PCR and its specificity for negative smears indicates its potential for retrospective analysis of stored, archival smears on slides.
\end{abstract}

Several techniques are available for the detection of the intracellular parasite Chlamydia trachomatis. ${ }^{1}$ These range from isolation in cultured cells, through direct fluorescence antibody (DFA) tests and enzyme immunoassays, to detection of DNA, the latest method involving DNA amplification by the polymerase chain reaction (PCR). When fresh clinical samples were examined we found that a PCR, in which primers have been used to amplify a fragment within the conserved region of the major outer membrane protein (MOMP) gene, ${ }^{2}$ matched in sensitivity and specificity a DFA test (MicroTrak, Syva), which uses a monoclonal antibody against the MOMP of the chlamydial elementary body.

A PCR has been used successfully to detect human papillomavirus (HPV) in sections of fixed tissue. ${ }^{3}$ We wished to determine whether $C$ trachomatis could be detected similarly in fixed and stained smears of exudate on slides that had been examined previously by the MicroTrak DFA test. The PCR would also be applied to the same material to make a direct comparison of the sensitivity and specificity of the two tests. Retrospective analysis of stored archival slides would also be possible. Processing of the sample for the PCR necessitated removal of material from the slide, the approach to which is described here.

\section{Methods}

A stock suspension of $C$ trachomatis (serovar H) was diluted serially in phosphate buffered saline (PBS) so that the final dilution contained $<10$ elementary bodies $/ 10 \mu \mathrm{l}$, as determined by a DFA test (MicroTrak, Syva), and undertaken as described previously. ${ }^{4}$ Aliquots $(10 \mu \mathrm{l})$ of the final dilution were then smeared on six MicroTrak slides, air dried, and fixed with acetone. Ten smears of PBS containing no elementary bodies were made and processed in the same manner. Thirty two smears of urethral exudate from men with non-gonococcal urethritis were also available after they had been examined by the DFA test. The exact number of elementary bodies in each of these smears was recorded; 27 of them contained elementary bodies and five did not.

For examination by the PCR, the material covered by a glass coverslip had to be removed from the slide. The coverslip was detached by prising it off with a needle, a process in which the edge nearest the needle point described an arc of $180^{\circ}$ pivoting on the opposite edge. In a preliminary experiment (results not shown) coverslips removed from chlamydia positive slides were not positive when examined by the PCR. Thereafter, coverslips were not examined. Sterile distilled water $(50 \mu \mathrm{l})$ was added to the slide using a positive displacement pipette and the surface of the slide was scraped with the needle to dislodge the material and suspend it in the water. Longitudinal, latitudinal, and circular patterns were described to scrape the slide and the suspension was collected using the positive displacement pipette and transferred to a $0.5 \mathrm{ml}$ microcentrifuge tube containing $50-100 \mu \mathrm{l}$ of mineral oil. The specimens were then boiled for 10 minutes and the target DNA was amplified as described previously. ${ }^{2}$ The amplified DNA products were run on $2 \%$ agarose gels, stained with ethidium bromide to give, if positive, a characteristic band of 379 base pairs. The results of the DFA tests were not revealed until those of the PCR were available.

\section{Results}

The number of positive smears and the number of elementary bodies detected by the DFA test (the "gold standard") were compared with the number of samples found positive by the PCR (table). Of the 33 slides recorded as positive in the DFA test, $24(73 \%)$ were positive by the PCR. These comprised 20 of 27 (74\%) urethral smears and four of six $(67 \%)$ dilutions of the stock strain of $C$ trachomatis. All samples containing five to 10 elementary bodies were found to be positive by the PCR, as were seven of $11(64 \%)$ smears each
Correspondence to:

Accepted for publication 8 October 1991 
Table Detection by the PCR of $C$ trachomatis elementary bodies on slides

\begin{tabular}{ccl}
\hline $\begin{array}{l}\text { No of elementary bod- } \\
\text { ies detected by DFA }\end{array}$ & No of slides tested & $\begin{array}{l}\text { No of slides positive } \\
\text { by the PCR }\end{array}$ \\
\hline $5-10$ & 6 & 6 \\
4 & 3 & 2 \\
3 & 4 & 3 \\
2 & 9 & 6 \\
1 & 11 & 7 \\
0 & 15 & 0 \\
\hline
\end{tabular}

containing only one elementary body. All 15 smears in which elementary bodies were not detected when examined by the DFA test were also negative when tested by the PCR, suggesting that they had not been contaminated with DNA.

\section{Discussion}

The technique of examining fixed smears on slides by the PCR is valuable in two respects. First, it provides further validation of the ability of the DFA test to detect small numbers of elementary bodies on slides, ${ }^{4}$ and at the same time the results confirm the sensitivity and specificity of the PCR for $C$ trachomatis. ${ }^{2}$ We regard it as remarkable that fixed and stained smears of material seen to contain one or two elementary bodies can be removed from a slide and shown almost always to be positive by the PCR. The organisms in these samples or their DNA apparently remained within the smears on the slides and there was nothing to be gained by also testing the coverslips. However, a smear is sometimes seen to be "floating" when examined by the DFA test. In this specific circumstance material on the underside of the coverslip should be rinsed off and added to the suspension on the slide. The practical value of the procedure we describe lies not only in its ability to confirm or refute, on the same specimen, results obtained previously by using the DFA test, but also in permitting retrospective examination of stored slides such as those, for example, of synovial fluid deposits from patients with sexually acquired reactive arthritis, ${ }^{5}$ for which the use of a confirmatory test would be of particular value.

1 Taylor-Robinson D, Thomas BJ. Laboratory techniques for the diagnosis of chlamydial infections. Genitourin Med the diagnosis of

2 Palmer HM, Gilroy CB, Thomas BJ, Hay PE, Gilchrist C, Taylor-Robinson D. Detection of Chlamydia trachomatis by the polymerase chain reaction in swabs and urine from men with non-gonococcal urethritis. $f$ Clin Pathol 1991; 44:321-5.

3 Shibata DK, Arnheim N, Martin WJ. Detection of human papilloma virus in paraffin-embedded tissue using the papillo 225-30.

4 Thomas BJ, Evans RT, Hawkins DA, Taylor-Robinson D. Sensitivity of detecting Chlamydia trachomatis elementary bodies in smears by use of a fluorescein labelled monoclonal antibody: comparison with convention

Keat A, Thomas B, Dixey J, Osborn M, Sonnex C, TaylorKeat A, Thomas B, Dixey J, Osborn M, Sonnex C, Taylor-
Robinson D. Chlamydia trachomatis and reactive arthritis: the missing link. Lancet 1987;i:72-4.
Division of Hospital Infection, Central Public Health Laboratory, Colindale, London

V Peiris

118 Lowndes Lane, Stockport, Cheshire J Heald

Correspondence to: DrV Peiris, Manchester Public Health Laboratory, Withington Hospital, Nell Lane, Manchester M20 8LR Accepted for publication 2 October 1991

\begin{abstract}
The ability of Branhamella catarrhalis to cause nosocomial infections is a matter of some controversy. The API ZYM research kit for detecting 89 enzymes was used on 49 isolates of $B$ catarrhalis to select enzymes of potential use in differentiating clinical isolates. Twenty nine enzymes were produced by all isolates (13 strongly positive) and many of these were esterases; 16 enzymes were not detected in any isolate (40 if a more stringent criterion was used). Twenty enzymes were selected to form a prototype biotyping panel which allowed 17 different patterns of reactivity to be recognised. Of the 49,34 isolates were confined to the three commonest
\end{abstract}

patterns. Only one isolate was untypable using this panel due to lack of reactivity. A kit with these 20 substrates may be sufficiently discriminatory to be useful in the rapid study of outbreaks of infection caused by $B$ catarrhalis.

Now widely accepted as a potential pathogen of the upper and lower respiratory tracts, Branhamella catarrhalis is also gaining recognition as a cause of conjunctivitis, meningitis, and septicaemia. ${ }^{1}$ Although often addressed as Moraxella (Branhamella) catarrhalis, proposals have once again been made to alter the taxonomic status of this organism. ${ }^{2}$ In recent years much attention has been focused on the 